\title{
Importance of the C-terminal domain of the human GW182 protein TNRC6C for translational repression
}

\author{
JAKOB T. ZIPPRICH, SANKAR BHATTACHARYYA, HANSRUEDI MATHYS, and WITOLD FILIPOWICZ \\ Friedrich Miescher Institute for Biomedical Research, 4058 Basel, Switzerland
}

\begin{abstract}
Proteins of the GW182 family play an important role in the execution of microRNA repression in metazoa. They interact directly with Argonaute proteins, components of microRNPs, and also form part of P-bodies, structures implicated in translational repression and mRNA degradation. Recent results demonstrated that Drosophila GW182 has the potential to both repress translation and accelerate mRNA deadenylation and decay. In contrast to a single GW182 protein in Drosophila, the three GW182 paralogs TNRC6A, TNRC6B, and TNRC6C are encoded in mammalian genomes. In this study, we provide evidence that TNRC6C, like TNRC6A and TNRC6B, is important for efficient miRNA repression. We further demonstrate that tethering of each of the human TNRC6 proteins to a reporter mRNA has a dramatic inhibitory effect on protein synthesis. The repression is due to a combination of effects on the mRNA level and mRNA translation. Through deletion and mutagenesis, we identified the C-terminal part of TNRC6C encompassing the RRM RNA-binding motif as a key effector domain mediating protein synthesis repression by TNRC6C.
\end{abstract}

Keywords: GW182; miRNA; RNA stability; translation; polyadenylation

\section{INTRODUCTION}

MicroRNAs (miRNAs) are 20- to 22-nucleotide (nt)-long noncoding RNAs regulating gene expression post-transcriptionally by base-pairing to target mRNAs. In animals, most investigated miRNAs form imperfect hybrids with sequences in the $3^{\prime}$-untranslated region $\left(3^{\prime}\right.$-UTR), with the miRNA $5^{\prime}$ proximal "seed" region (positions 2-8) providing most of the pairing specificity (for review, see Bartel 2004; Bushati and Cohen 2007; Filipowicz et al. 2008). Generally, the miRNA association results in translational repression, frequently accompanied by considerable degradation of mRNA (Nilsen 2007; Standart and Jackson 2007; Eulalio et al. 2008a; Filipowicz et al. 2008; Wu and Belasco 2008). More recently, however, miRNAs were also found to have the potential to activate translation (Vasudevan et al. 2007, 2008; Orom et al. 2008). For example, in nonproliferating cells or cells in the $\mathrm{G}_{0}$ cell cycle phase, miRNAs were reported to stimulate rather than inhibit protein synthesis (Vasudevan et al. 2007, 2008).

Reprint requests to: Witold Filipowicz, Friedrich Miescher Institute for Biomedical Research, Maulbeerstrasse 66, 4058 Basel, Switzerland; e-mail: Filipowi@fmi.ch; fax: 41-61-6973976.

Article published online ahead of print. Article and publication date are at http://www.rnajournal.org/cgi/doi/10.1261/rna.1448009.
miRNAs function as components of ribonucleoprotein (RNP) complexes, miRNPs. The best-characterized constituents of miRNPs are proteins of the Argonaute (AGO) family. Their function in miRNA-mediated repression is well documented in many organisms (Peters and Meister 2007; Tolia and Joshua-Tor 2007). Mammals contain four AGO proteins, AGO1-4, associating with similar sets of miRNAs and participating in translational repression (Liu et al. 2004; Meister et al. 2004). In Drosophila, Ago1 is dedicated to the miRNA pathway while Ago2 mainly functions in RNA interference (RNAi) (Peters and Meister 2007; Tolia and Joshua-Tor 2007). The Ago proteins repress protein synthesis when artificially tethered to the mRNA 3'-UTR, indicating that they function as downstream effectors in the repression, with miRNAs mainly acting as guides bringing the proteins to mRNA targets (Pillai et al. 2004, 2005; Rehwinkel et al. 2005; Wu et al. 2008).

Argonautes are not the only proteins required for the miRNA-mediated repression. Several components of P-bodies (known also as GW-bodies), which are cytoplasmic structures involved in the degradation and storage of translationally repressed mRNAs (Eulalio et al. 2007a; Parker and Sheth 2007), also function in the miRNA pathway and, consistently, repressed mRNAs, miRNAs, and Ago proteins are enriched in P-bodies (Liu et al. 2005; Pillai et al. 2005; Sen and Blau 2005; Huang et al. 2007; for review, see Jakymiw 
et al. 2007; Eulalio et al. 2008a; Filipowicz et al. 2008). Of the P-body components, proteins of the GW182 family play a particularly important role in the execution of miRNA repression. GW182 proteins, characterized by the presence of multiple Gly-Trp (GW) repeats (Eystathioy et al. 2002; Ding et al. 2005; Rehwinkel et al. 2005; Schneider et al. 2006), interact with Argonautes through their GW-rich domain (Behm-Ansmant et al. 2006; Till et al. 2007; Eulalio et al. 2008b). Recent work carried out in the Drosophila system demonstrated that this interaction is essential for the repression (Till et al. 2007; Eulalio et al. 2008b). Importantly, tethering of GW182 to the mRNA bypassed the Agol requirement for repression in Drosophila cells, demonstrating that GW182 functions in the same pathway but downstream from Ago1 (Behm-Ansmant et al. 2006).

Despite a considerable research effort, the mechanistic details of miRNA function in repressing protein synthesis are still poorly understood. Moreover, the results from studies conducted in different systems and different laboratories have often been contradictory, making it difficult to obtain a lucid picture of the repression (Nilsen 2007; Standart and Jackson 2007; Eulalio et al. 2008a; Filipowicz et al. 2008; Wu and Belasco 2008). Although many experiments investigating miRNA function in metazoan cells or in vitro point to the initiation of translation as a target of miRNA repression (Humphreys et al. 2005; Pillai et al. 2005; Bhattacharyya et al. 2006; Chendrimada et al. 2007; Kiriakidou et al. 2007; Mathonnet et al. 2007; Wakiyama et al. 2007), there is also considerable evidence that miRNAs inhibit translation at post-initiation steps (Olsen and Ambros 1999; Maroney et al. 2006; Nottrott et al. 2006; Petersen et al. 2006; Lytle et al. 2007). Although reports aimed at the reconciliation of some conflicting data have appeared recently (Kong et al. 2008), the question of whether the disparities represent artifacts of different experimental approaches or whether miRNAs are indeed able to repress protein synthesis by different mechanisms remains one of the key problems to be resolved (Nilsen 2007; Eulalio et al. 2008a; Filipowicz et al. 2008).

Another important and unanswered issue is the relative contribution of translational inhibition and mRNA degradation to the final outcome of the repression. Most investigated mRNAs undergo moderate or substantial degradation, which appears to be initiated by removal of the poly $(\mathrm{A})$ tail in response to miRNP association with the mRNA 3'-UTR (Bagga et al. 2005; Lim et al. 2005; Wu and Belasco 2005; Behm-Ansmant et al. 2006; Giraldez et al. 2006; Rehwinkel et al. 2006; Schmitter et al. 2006; Eulalio et al. 2007b). In Drosophila, the GW182 protein is implicated in the recruitment of deadenylating enzymes to the mRNA, although the protein also functions in translational repression independently of its role in deadenylation (BehmAnsmant et al. 2006). However, many mRNAs repressed by miRNAs are resistant to degradation (for a comprehensive list, see Filipowicz et al. 2008). Which features of mRNA or of the mRNA-miRNA interaction determine whether repression follows translational inhibition or mRNA decay? Is the latter a consequence of translation being repressed, or does it occur independently of the translational status of the mRNA?

In contrast to the single GW182 protein expressed in Drosophila, three GW182 paralogs, TNRC6A, TNRC6B, and TNRC6C, are encoded in mammalian genomes (for review, see Ding and Han 2007; Jakymiw et al. 2007). Evidence has already been presented that the two human proteins TNRC6A and TNRC6B function in the miRNA pathway and are important for effective miRNA repression (Jakymiw et al. 2005; Liu et al. 2005; Meister et al. 2005; Till et al. 2007). However, mechanistic details of the repression have not been investigated for any of the mammalian proteins. In this study, we provide evidence that TNRC6C, like TNRC6A and TNRC6B, is essential for efficient miRNA repression and demonstrate that tethering of each of the human GW182 proteins to reporter mRNA has a dramatic effect on protein synthesis, with only a moderate effect on mRNA stability. Finally, we identify the C-terminal fragment of TNRC6C, encompassing the RNAbinding RRM motif, as a region mediating the repression. Two other domains, GW-rich and Q-rich, also repress protein synthesis upon tethering, but their effects are much less pronounced than that of the C-terminal region.

\section{RESULTS}

\section{Human GW182 protein TNRC6C is involved in miRNA-mediated repression}

The three GW182 protein paralogs encoded in mammalian genomes, TNRC6A, TNRC6B, and TNRC6C, have a domain organization similar to Drosophila GW182 (also known as Gawky). At the N-proximal part, they contain a domain rich in GW or WG repeats followed by a glutamine (Q)-rich region of unknown function, hereafter referred to as DUF, and an RNA-binding domain, RRM. The Drosophila GW182 and mammalian TNRC6C also contain a central ubiquitinassociated (UBA) domain (Fig. 1A; for review, see Ding and Han 2007). Two homologs of GW182 proteins, AIN-1 and AIN-2, were characterized in Caenorhabditis elegans. While AIN-1 and AIN-2 both contain GW- and Q-rich sequences, they lack other domains present in mammalian proteins (Ding et al. 2005; Zhang et al. 2007). Interestingly, through database searches, we have identified a likely homolog of TNRC6 and AIN proteins in the nematode Brugia malayi. In addition to GW-containing and Q-rich sequences, this protein includes a DUF domain (Fig. 1A,B). Hence, the B. malayi protein likely represents an evolutionary link between TNRC6 and AIN proteins.

The TNRC6A and TNRC6B proteins were demonstrated previously to play a role in the miRNA pathway in mammalian cells (Jakymiw et al. 2005; Liu et al. 2005; Meister et al. 2005), but the expression and function of TNRC6C have not been investigated. We raised polyclonal 
A

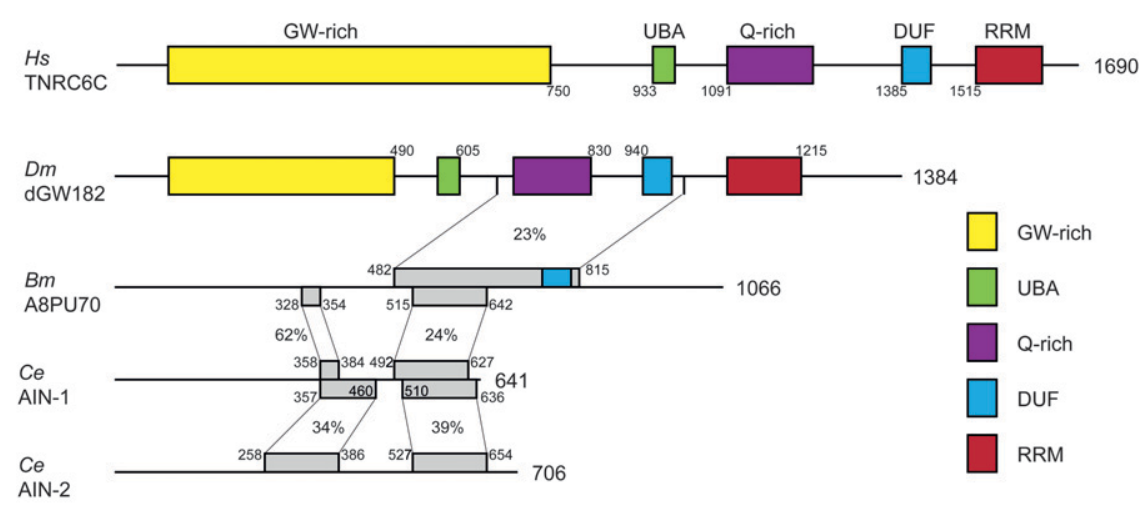

B

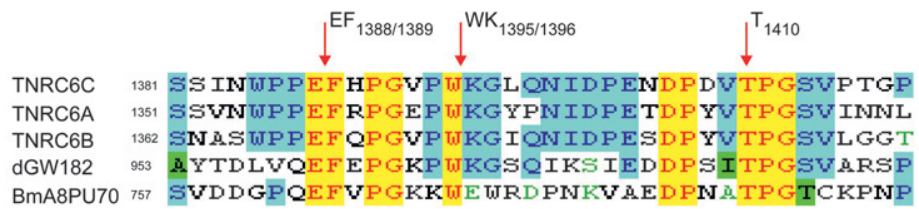

FIGURE 1. Domain structure of selected GW-182-like proteins. (A) Schematic representation of human (Hs) TNRC6A, TNRC6B, and TNRC6C proteins, the Drosophila (Dm) GW182 (dGW182), C. elegans (Ce) AIN-1 and AIN-2, and a candidate GW182 ortholog of Brugia malayi (Bm). Positions of GW-rich, Q-rich, UBA (ubiquitin-associated), DUF (domain of unknown function), and RRM domains are indicated. The percentage of amino acid identity between highlighted regions of Drosophila, C. elegans, and B. malayi proteins is indicated. (B) Amino acid alignments of DUF domains of selected GW proteins. Positions of amino acids that have been mutated to alanines, either singly (T1410) or in the combination of two (EF1388/1389 and WK1395/1396), are indicated. (Blue) Amino acids identical in more than $50 \%$ of proteins; (green) conservative substitutions by related amino acids.

antibodies (Abs) against peptides with sequence present in TNRC6C but not two other mammalian GW182 proteins. In Western analysis, the affinity-purified $\mathrm{Ab}$ recognized a protein of the expected size in lysates prepared from HEK293 and HeLa cells. The intensity of the recognized band was weaker in lysates of cells in which TNRC6C was knocked down by RNAi (Fig. 2A, lanes 7-10). Overexpression of the HA-tagged version of the protein further confirmed that the visualized band corresponds to TNRC6C (lane 6). The $\mathrm{Ab}$ did not recognize overexpressed TNRC6A and TNRC6B (Fig. 2A, lanes 4,5), consistent with it being specific for TNRC6C. RT-PCR analysis with primers specific for individual GW182 genes revealed that all three TNRC6 genes are expressed in both HEK293 and HeLa cells (data not shown).

To find out whether TNRC6C, like TNRC6A and TNRC6B (Jakymiw et al. 2005; Liu et al. 2005; Meister et al. 2005), is required for miRNA-mediated repression, we knocked it down using RNAi. As controls, TNRC6A and TNRC6B were also individually depleted using gene-specific siRNAs. The efficacy of the knockdowns was monitored by following the levels of either ectopically expressed HAtagged TNRC6 proteins (Fig. 2B) or the endogenous
TNRC6C (Fig. 2A). For siRNAs directed at TNRC6B and TNRC6C, we verified that their effects were target-specific (data not shown). As illustrated in Figure 2C, down-regulation of each TNRC6 protein partially rescued repression of the Renilla luciferase (RL) reporter, RL-3xBulgeB. RL-3xBulgeB harbors in its $3^{\prime}$-UTR three sites specific for let-7b miRNA (Pillai et al. 2005; Schmitter et al. 2006), which is abundantly expressed in HeLa cells. We conclude that TNRC6C plays a role similar to those of TNRC6A and TNRC6B, although the observation that knockdown of each individual protein had a marked effect on miRNA repression leaves open the possibility that the functions of individual TNRC6 paralogs in mediating miRNA-mediated inhibition do not entirely overlap.

\section{Tethering of TNRC6 proteins to mRNA causes repression of protein synthesis}

We used a tethering approach to investigate the effect of individual mammalian TNRC6 paralogs on protein synthesis. In this assay, which was used successfully to study functions of AGO proteins (Pillai et al. 2004; Rehwinkel et al. 2005; Kiriakidou et al. 2007; Wu et al. 2008) and the Drosophila GW182 (dGW182) (Behm-Ansmant et al. 2006), the proteins are expressed as fusions with the HA-tag and the phage $\lambda \mathrm{N}$ peptide, which specifically recognizes box $\mathrm{B}$ hairpins inserted into the $3^{\prime}$-UTR of RL-5BoxB reporter. The RL expression was normalized to the activity of firefly luciferase (FL) expressed from the co-transfected plasmid bearing no 5BoxB hairpins (FL-Con). As shown in Figure 3, expression of the NHA version of each of the three TNRC6 proteins strongly repressed activity of the RL-5BoxB reporter when compared to control TNRC6 proteins containing the HA-tag but lacking the N peptide. Tethering of NHA-LacZ, used as another control, yielded RL activity similar to that measured in the presence of HA-TNRC6C (see also Figs. 6A and 8, below; data not shown). Together with Western analysis, which revealed similar expression levels of NHA- and HA-tagged proteins (Fig. 3A), the data demonstrate that the repression of protein synthesis is a result of the TNRC6 proteins tethering to mRNA.

To find out whether the tethered TNRC6 proteins repress RL activity by inhibiting translation or destabilizing the mRNA, we quantified RL-5BoxB mRNA levels and, as a reference, the levels of GFP mRNA coexpressed in transfected 
A

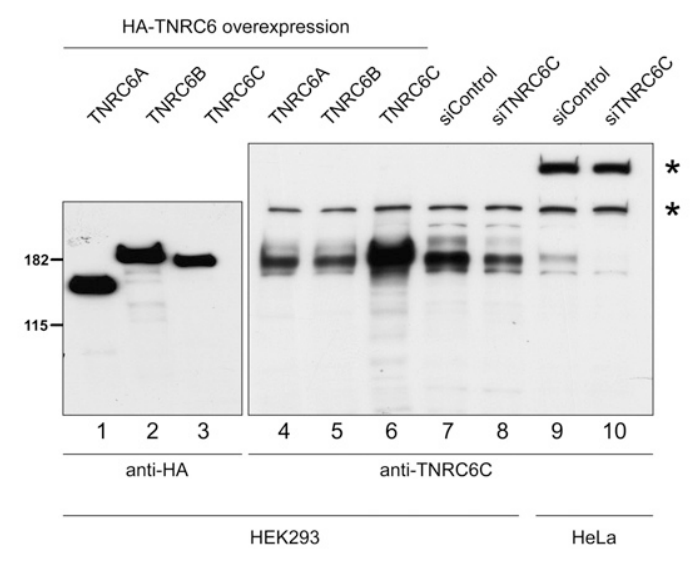

B

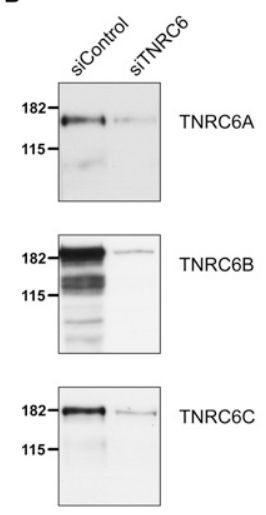

C
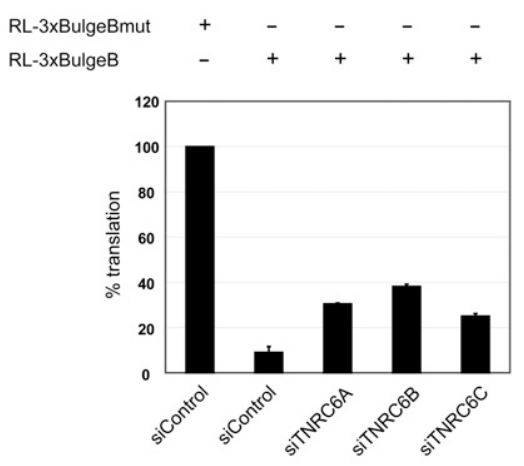

FIGURE 2. Expression of TNRC6C protein in HEK293 and HeLa cells and its importance for effective miRNA-mediated repression. (A) AntiTNRC6C Abs specifically recognize endogenous TNRC6C in HEK293 and HeLa cell extracts and do not cross-react with overexpressed TNRC6A and TNRC6B proteins. (Lanes 1-6) Extracts prepared from HEK293 cells overexpressing indicated HA-TNRC6 proteins; (lanes 710) extracts of HEK293 or HeLa cells transfected with either control or anti-TNRC6 siRNAs. Abs used for Western analysis and positions of protein size markers are indicated. $\left.{ }^{*}\right)$ Non-specific proteins crossreacting with anti-TNRC6C Ab. Note that overexpression of TNRC6A or TNRC6B proteins slightly decreases the level of endogenous HTNRC6C (cf. lanes 4,5 and lane 7). (B) Knockdown of individual TNRC6 proteins by specific siRNAs. Cells were cotransfected with constructs expressing indicated NHA-tagged TNRC6 proteins and either gene-specific or control siRNAs. One siRNA was used in the case of TNRC6A, and mixtures of two in the case of TNRC6B and TNRC6C (Materials and Methods). Anti-HA Ab was used for Western blot analysis. $(C)$ TNRC6C, similarly to TNRC6A and TNRC6B, is required for efficient repression of RL-3xBulgeB reporter by endogenous let-7 in HeLa cells. Down-regulation of each protein partially rescues repression of RL-3xBulgeB. RL-3xBulgeBmut, containing mutations in the seed sequence of the let- 7 binding that prevent the repression (Pillai et al. 2005; Schmitter et al. 2006), was used as a control reporter. SiRNAs used for knockdowns are indicated. The data represent means from three independent experiments.

cells. Comparison of RL activity (Fig. 3A) and Northern blot data (Fig. 3B) revealed that tethering of TNRC6 proteins to RL-5BoxB mRNA had a much stronger effect on protein expression (10- to 20-fold) than on mRNA levels (approximately threefold), indicating that all three TNRC6 proteins not only trigger marked mRNA destabilization but also directly affect the translation process itself.

\section{Identification of repressive domains of TNRC6C by deletion analysis}

To gain insight into the mechanism of TNRC6C-mediated repression, we generated a collection of deletion mutants of the protein and tested their effects on protein synthesis using the tethering assay. Progressive deletions from the $\mathrm{N}$ terminus of the protein (Fig. 4A) revealed that a fragment bearing only the C-proximal domains DUF and RRM (mutant $\Delta \mathrm{N} 1370$ ) retained the potential to inhibit $\mathrm{RL}$ activity upon tethering to mRNA (Fig. 4B). Quantification of the data derived from many experiments in which effects of NHA-TNRC6C and NHA- $\Delta$ N1370 were compared indicated that repression by NHA- $\Delta$ N1370 was actually stronger than that by a full-length NHA-TNRC6C (for significance of the difference, see Fig. 5C and its legend), raising a possibility that the N-terminal portion of TNRC6C may modulate inhibitory activity of the C-terminal $\Delta \mathrm{N} 1370$. Further truncation of NHA- $\Delta \mathrm{N} 1370$, leading to the removal of DUF (mutant $\Delta \mathrm{N} 1471$ ), decreased the repressive activity, but this mutant still inhibited protein synthesis approximately fourfold compared with the more than 10-fold repression seen with $\Delta \mathrm{N} 1370$ (Fig. $4 \mathrm{~B}$ ). In the analysis of mutants with progressive $\mathrm{N}$-terminal deletions and of most of the other mutants described below, care was taken to assess mutant proteins expressed at similar levels (Fig. 4B). This sometimes required the adjustment of amounts of mutant-encoding plasmids transfected into cells (see Materials and Methods). However, within the range of plasmid concentrations used for transfections, the extent of repression caused by individual mutants was generally independent of the amount of transfected plasmid.

In a further set of mutants, progressive deletions were carried out from the $\mathrm{C}$ terminus (Fig. 4A). As expected, deletion of the C-terminal portion of TNRC6C containing the DUF and RRM domains strongly affected the repressive potential of the protein. Interestingly, analysis of other mutants revealed that the N-terminal half of the GW-rich domain (Fig. 4A, mutant 1-405) and a fragment encompassing the entire GW-rich domain and the UBA domain (Fig. 4A, mutant 1-1034) each had some repressive activity: their tethering inhibited protein synthesis $\sim 40 \%$ (Fig. $4 \mathrm{C}$ ). Tethering of the Q-rich domain alone (Fig. 4A, mutant 1080-1245) also caused an $\sim 65 \%$ repression of RL activity. The repressive activity of a fragment encompassing both the GW- and Q-rich domains (Fig. 4A, mutant 1-1368) was not stronger than the individual domains alone.

\section{The integrity of the $\Delta \mathrm{N} 1370$ fragment is important for effective repression}

Since deletion analysis revealed that the C-terminal fragment of TNRC6C (Fig. 5C, mutant $\Delta \mathrm{N} 1370$ ) repressed 
A

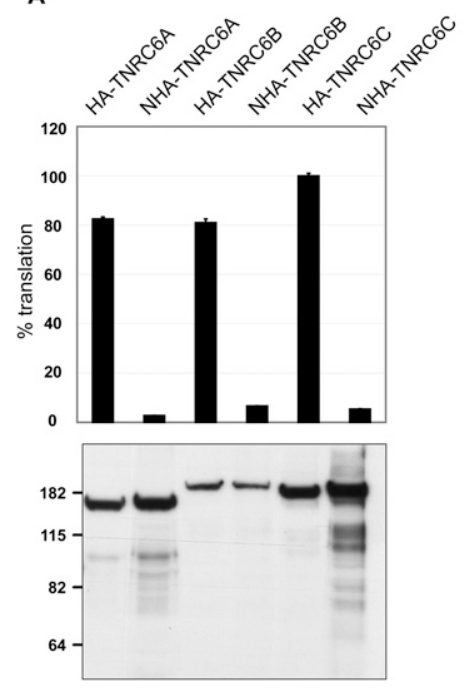

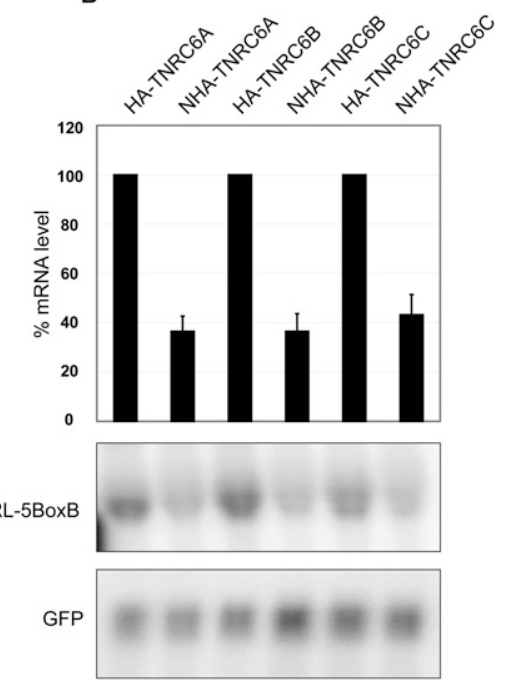

FIGURE 3. Tethering of TNRC6 proteins to mRNA causes strong repression of protein synthesis and partial mRNA degradation. (A) Indicated HA- or NHA-tagged TNRC6 proteins were coexpressed into HEK293 cells with RL-5BoxB, FL-Con, and (in some transfections) GFP reporters. (Upper panel) RL expression was normalized to the activity of FL and is shown as the percentage of activity seen in the presence of HA-TNRC6C. Tethering of NHA-LacZ protein, frequently used as an additional control (see Figs. 6 and 8), did not repress protein synthesis. (Lower panel) Representative Western analysis of expressed proteins, performed with anti-HA Ab. (B) Northern blot analysis of RL-5BoxB and GFP mRNAs levels. (Upper panel) PhosphorImaging quantification of RL-5BoxB mRNA, normalized to GFP mRNA. (Bottom panels) Representative Northern blot analysis. Values in $A$ and $B$ are means from three independent experiments. Values for cells expressing HA-tagged proteins were set to $100 \%$.

protein synthesis even more effectively than the full-length protein, we focused our attention on this region. Repressive activity of GW- and Q-rich domains was relatively small and was not further investigated. The integrity of the $\Delta$ N1370 fragment appeared to be important since deletion of either the N-proximal DUF domain or $80 \mathrm{C}$-terminal amino acids resulted in a significant decrease of the repression. In addition, isolated RRM domain (Fig. 5C, fragment NHA-1505-1610) was devoid of repressive potential (Fig. 5C, left part).

RNP1 and RNP2 motifs present in the RRM domains of many characterized RNA-binding proteins contain aromatic residues involved in stacking interactions with RNA ligands (Clery et al. 2008). Similarly, the RRM domains of GW182 proteins contain several conserved aromatic amino acids, both within and outside of RNP1 and RNP2 motifs (Fig. 5B). Residues W1515, H1537, F1543, Y1556, and F1583 were individually mutated to alanine in the context of the $\Delta$ N1370 fragment. In another mutant, residues H1537 and Y1556 were simultaneously replaced with alanine. Several of the RRM mutants had a significantly lower activity in repressing protein synthesis than the wildtype $\Delta \mathrm{N} 1370$ fragment (Fig. 5C, right part).

We also generated single or double amino acid mutations in some conserved residues of the DUF domain (for the identities of the mutated amino acids, see Fig. 1B). However, these mutations had no appreciable effect on the ability of the $\Delta \mathrm{N} 1370$ fragment to repress protein synthesis in the tethering assay (data not shown).

\section{The $\Delta \mathrm{N} 1370$ fragment acts mainly as a translational repressor}

To find out whether the $\Delta \mathrm{N} 1370$ fragment acts similarly to the full-length TNRC6C and affects both mRNA translation and stability, we examined the level of RL-5BoxB reporter repressed by tethering of the $\Delta$ N1370 fragment or its RRM domain mutants. Comparison of Northern blotting and RL activity data originating from the same transfection experiments indicated that tethering of $\Delta \mathrm{N} 1370$ results in an approximately twofold decrease in mRNA level under conditions leading to an approximately 20fold drop in RL activity (Fig. 6A). Hence, the inhibitory effect of $\Delta \mathrm{N} 1370$ on RL expression is due mainly to repression of translation. After correction for differences in mRNA levels, the net effect of the tethering of $\Delta \mathrm{N} 1370$ on translation was 10-fold (Fig. 6A). Tethering of the two tested $\triangle \mathrm{N} 1370$ RRM domain mutants also decreased the RL-5BoxB mRNA level twofold but did not inhibit protein synthesis as much as the wild-type $\Delta \mathrm{N} 1370$. The net effect of the F1543A and H1537A/Y1556A mutants on translation was only approximately 2.5 -fold, compared with the 10-fold effect of $\Delta$ N1370 (Fig. 6A). This suggests that the RRM domain functions in translational repression rather than in mRNA destabilization.

We investigated whether the repressive effect on translation seen upon tethering of TNRC6C and its $\Delta \mathrm{N} 1370$ deletion mutants could be due to mRNA deadenylation. Total RNA isolated from cells transfected with vectors expressing different proteins was subjected to RNase $\mathrm{H}$ treatment in the presence or the absence of oligo(dT). Incubation in the presence of oligo $(\mathrm{dT})$ should result in removal of poly(A) from mRNA and, consequently, in its faster mobility in an agarose gel. Where the mRNA has been deadenylated already in the cell, no major difference in its mobility would be expected upon RNase $\mathrm{H}$ digestion. As shown in Figure 6B, control RL-Con RNA isolated from cells co-transfected with NHA-TNRC6C or RL-5BoxB RNA isolated from cells co-transfected with HATNRC6C contained poly(A) tracts since their mobility increased upon oligo(dT) addition. Likewise, the mobility of $\beta$-actin mRNA, analyzed as an additional control, increased upon removal of poly(A) in vitro. Importantly, RL-5BoxB RNA preparations isolated from cells transfected with either NHA-TNRC6C or NHA- $\Delta$ N1370 deletion 
A

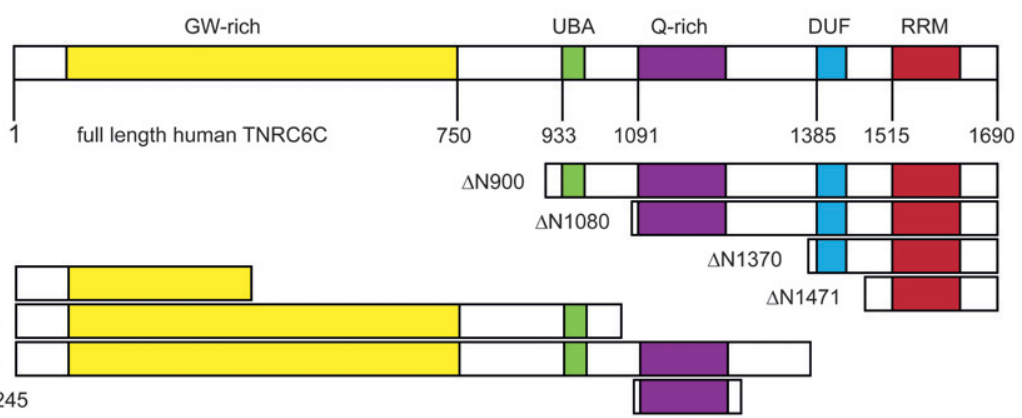

B
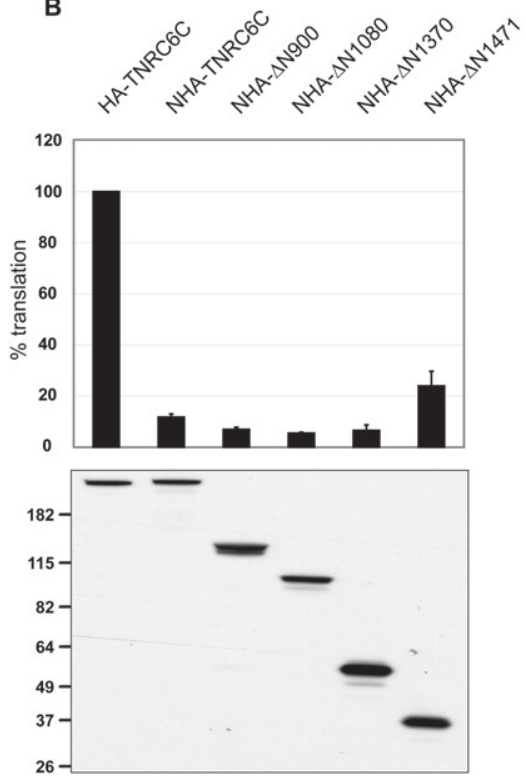

FIGURE 4. of TNRC6C and its deletion mutants. Mutants with progressive deletions from the (upper part of scheme) $\mathrm{N}$ terminus and (lower part of scheme) C terminus. Numbers correspond to amino acid positions. (B) The C-terminal domain of TNRC6C is sufficient to effectively repress protein synthesis when tethered to mRNA. (Upper panel) Repressive activity of TNRC6C and its N-terminal deletion mutants. HEK293 cells were co-transfected with plasmids expressing $\mathrm{N}-\mathrm{HA}$ fusions of TNRC6C or its fragments and plasmids encoding RL-5BoxB and FL reporters. HA-TNRC6C served as a negative control. Activity of RL was normalized for expression of FL. Values represent relative RL activities normalized to FL, with translation in the presence of HA-TNRC6C set as 100\%. (Lower panel) Expression levels of HA-TNRC6C and NHA-TNRC6C and its mutants as assessed by Western blotting using anti-HA Ab. Positions of protein size markers are indicated. $(C)$ Analysis of progressive deletion mutants from the $C$ terminus and the 1080-1245 mutant reveals only moderate repressive activity of GW- and Q-rich domains. Details of experiments are identical to those given in the legend to Figure $4 \mathrm{~B}$. The values in $B$ and $C$ are means ( \pm SEM) from four to 12 independent experiments. Expression of the Q-rich domain was reproducibly weaker than of other domains.

mutants also changed their mobility after incubation with oligo $(\mathrm{dT})$, consistent with them retaining the poly $(\mathrm{A})$ tail (Fig. 6B). These data indicate that the inhibitory effect of tethering TNRC6C or $\Delta \mathrm{N} 1370$ on translation is not due to elimination of a stimulatory role of the poly(A)-binding protein PABP on translation initiation (Kahvejian et al. 2005) or due to disruption of mRNA "circularization" (Wells et al. 1998) potentially caused by mRNA deadenylation.

\section{The $\Delta$ N1370 fragment does not interact with endogenous AGO or TNRC6C proteins}

We considered the possibility that the inhibitory effect of $\Delta$ N1370 on protein synthesis is due to the interaction of this fragment with endogenous TNRC6 or AGO proteins. If this were the case, the inhibition would not be due to the downstream function of $\Delta \mathrm{N} 1370$ in miRNA-mediated repression but due to recruitment of the endogenous miRNP complex to the reporter mRNA. Using immunoprecipitation (IP) assays, we first determined whether NHA- $\Delta$ N1370 expressed in HEK293 cells interacts with endogenous AGO proteins or TNRC6C. Neither AGO proteins nor TNRC6C were pulled down with the anti-HA Ab but, as expected (Behm-Ansmant et al. 2006; Till et al. 2007), the full-length NHA-TNRC6C and its N-terminal GWrich fragment NHA-1-1034 very effectively coimmunoprecipitated the endogenous Argonautes (Fig. 7A). Since specific Abs recognizing TNRC6A and TNRC6B proteins are not available, we have coexpressed HA-tagged versions of these proteins together with either Flag-HA-tagged $\Delta \mathrm{N} 1370$ or Flag-HA-tagged AGO2, the latter protein used as a control. IP experiments with anti-Flag Abs revealed that AGO2 but not $\Delta \mathrm{N} 1370$ is able to interact with TNRC6A and TNRC6B proteins (Fig. 7B). We conclude that the $\Delta \mathrm{N} 1370$ fragment functions as an autonomous repressive domain, the inhibitory effect of which is not caused by interaction with Argonautes or full-length TNRC6 proteins.

\section{Cross-species repressive activity of GW proteins and their mutants}

In the accompanying manuscript, Chekulaeva et al. (2009) have identified three nonoverlapping regions of the Drosophila GW182 (dGW182) protein that are able to repress protein synthesis effectively (five- to sixfold) upon tethering to mRNA: the N-terminal GW-rich domain, the Q-rich domain, and the C-proximal fragment containing DUF and RRM domains (for a scheme of dGW182, see Fig. 1A). We tested the potential of the full-length dGW182 and its active subfragments to inhibit the activity of the RL5 BoxB reporter in HEK293 cells. Tethering of a full-length 


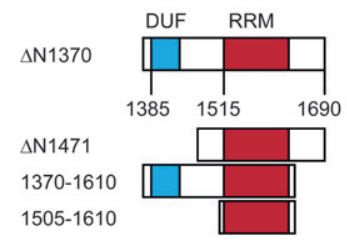

B

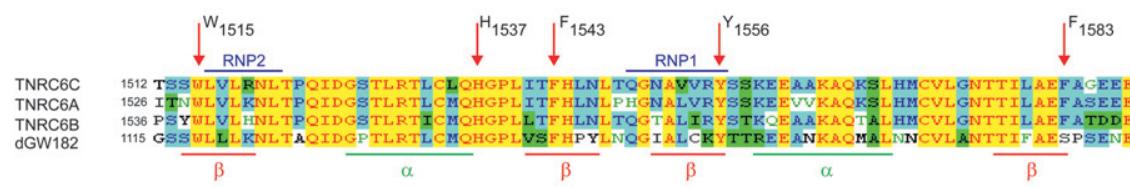

C

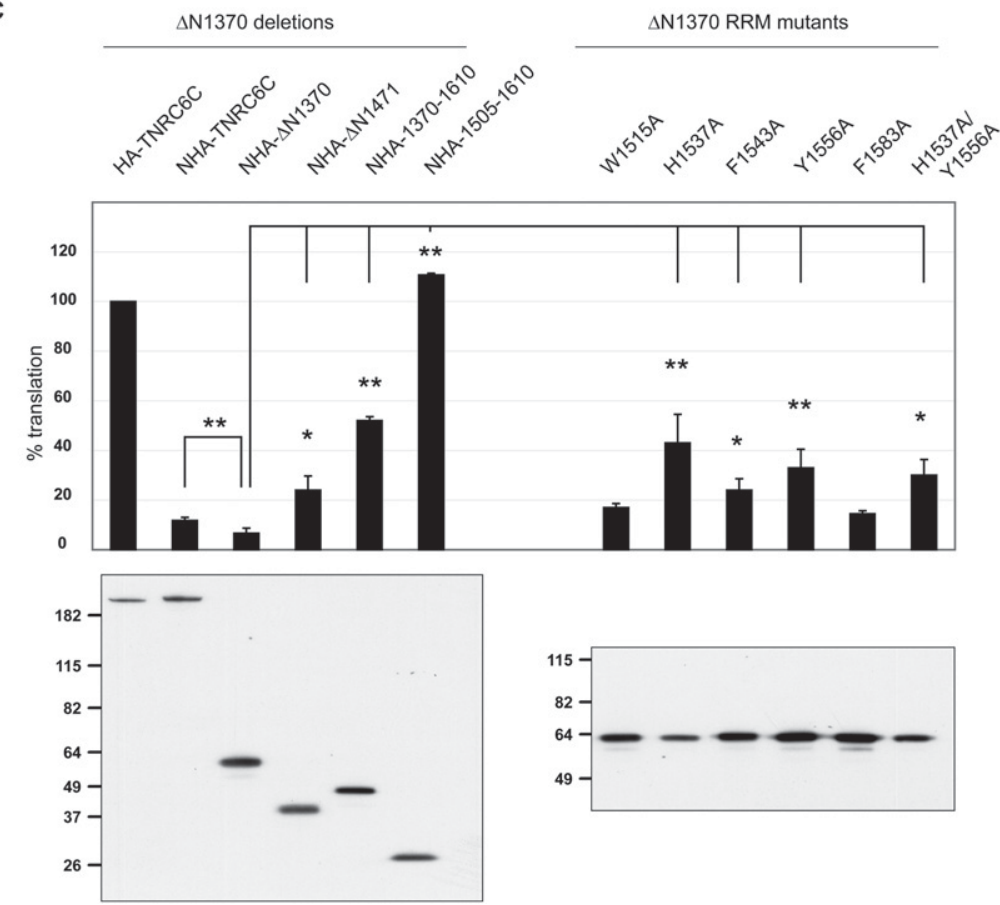

FIGURE 5. Detailed characterization of the C-terminal $\Delta$ N1370 fragment of TNRC6C. $(A)$ Schematic representation of deletion mutants of the C-terminal $\Delta$ N1370 fragment of TNRC6C (B) Sequence alignment of RRM domains of selected GW182 proteins. Aromatic amino acids mutated to alanines, either singly or in combination (mutant H1537/Y1556), are indicated. RNP1 and RNP2 motifs are overlined. Positions of $\alpha$-helices and $\beta$-sheets predicted for the TNRC6C RRM using Phyre (http://www.sbg.bio.ic.ac.uk/phyre/) are shown below the alignment. (C, upper panel) Repressive activity of mutants of the $\Delta \mathrm{N} 1370$ fragment shown in panel $A$. Cells were cotransfected with plasmids expressing NHA fusions of TNRC6C or the $\Delta \mathrm{N} 1370$ fragment and its mutants, and the reporter plasmids. Values represent the percent of translation as measured by normalized RL activity, with translation in the presence of HA-TNRC6C taken as $100 \%$. Error bars show standard error $(n=3-12)$. Statistical significance (NHA-TNRC6C versus NHA$\Delta$ N1370 and NHA- $\Delta$ N1370 versus other deletion and RRM amino acid mutants) was calculated using the nonparametric Mann-Whitney-Wilcoxon test (NHA-TNRC6C versus NHA- $\Delta$ N1370) or paired two-tailed Student's $t$-test (all other comparisons); $\left(^{*}\right) P<0.05 ;\left({ }^{*}\right) P<0.01$. (Lower panels) Expression levels of HA-TNRC6C, NHA-TNRC6C, and the C-terminal $\Delta$ N1370 fragment and its mutants as assessed by Western blotting using anti-HA Ab.

NHA-dGW182 repressed RL activity as efficiently as the mammalian NHA-TNRC6C; expression of HA-dGW182 had no inhibitory effect. Interestingly, the N-terminal GWrich domain (mutant 1-605) of dGW182 was the most active repressor in human cells; its repressive activity (approximately sevenfold) was comparable to that seen in Drosophila S2 cells (approximately sixfold). In contrast, three further dGW182 fragments tested (Q-rich domain, mutant 605-803, and two C-terminal fragments encompassing DUF and RRM domains, mutants 9401385 and 940-1215) repressed RL activity in HEK293 cells only approximately twofold (Fig. 8).

In a reciprocal cross-species experiment, different domains of TNRC6C characterized in this work were tested in Drosophila S2 cells. A full-length TNRC6C inhibited activity of the tethering reporter approximately sixfold, while the GW-rich (1-1034), Q-rich (1080-1245), and the C-terminal $\Delta \mathrm{N} 1370$ fragment repressed protein synthesis $\sim 1.5$-fold, eightfold, and 20-fold, respectively (Chekulaeva et al. 2009). Hence, although the fulllength dGW182 and TNRC6C proteins exerted a similar strong repressive effect irrespective of whether they were tested in the homologous or heterologous system, the contribution of individual domains to this effect differed between human and Drosophila proteins and cells (see Discussion).

\section{DISCUSSION}

Proteins of the GW182 family play an important role in the miRNA-mediated repression in metazoa. They directly interact with AGO proteins and appear to function as downstream effectors in the miRNA pathway, responsible for inhibition of translation and acceleration of mRNA decay (Jakymiw et al. 2005; Liu et al. 2005; Meister et al. 2005; Rehwinkel et al. 2005; Behm-Ansmant et al. 2006; Till et al. 2007; Zhang et al. 2007). In contrast to a single GW182 protein expressed in Drosophila, three paralogs, TNRC6A, TNRC6B, and TNRC6C, are encoded in mammalian genomes but little is known about their functions. In this study, we provide evidence that TNRC6C, like TNRC6A and TNRC6B studied previously, is expressed in HEK293 and HeLa cells and is essential for the efficient repression of a target mRNA reporter by endogenous let-7 miRNP. More important, we demonstrate that tethering of each human 
TNRC6 protein to reporter mRNA strongly affects a process of translation, with a more moderate effect on mRNA stability. We show that the effect on translation is not due to the remaining mRNA being deadenylated. We identify $\Delta \mathrm{N} 1370$, the C-terminal fragment of TNRC6C including the RRM RNA-binding motif, as a key region mediating the translational repression of TNRC6C. Two other domains, GW-rich and Q-rich, also repress protein synthesis upon tethering but only approximately twofold. The $\Delta$ N1370 fragment appears to function as an autonomous domain, the inhibitory function of which does not involve interaction with AGO or TNRC6 family proteins.

Human TNRC6A and TNRC6B were previously identified as AGO-interacting proteins, and their knockdown was shown to affect the efficiency of miRNA-mediated repression (Jakymiw et al. 2005; Liu et al. 2005; Meister et al. 2005; Till et al. 2007). Results of knockdown and co-IP experiments presented in this report extend these conclusions to TNRC6C. Involvement of TNRC6C in miRNA regulation is also supported by recent IP experiments of Landthaler et al. (2008). Our demonstration that individual tethering of each of the three TNRC6 proteins dramatically inhibits mRNA translation adds further evidence to the repressive functions of these proteins. It is intriguing that individual knockdown of each of the three TNRC6 proteins markedly interferes with miRNA repression despite their similar domain organizations. It remains to be established whether this is due to not entirely overlapping functions of individual TNRC6 paralogs in miRNA repression or is a consequence of the decreased total pool of TNRC6 proteins in the cell. Following submission of our manuscript, Li et al. (2008) reported that tethering of TNRC6A also represses translation of FL reporter in HEK293 cells but only by approximately threefold. In a total of 15 independent transfection experiments performed by us in HEK293 cells, inhibition of RL reporter by tethering of TNRC6C varied between 6.5-fold and 18-fold. In HeLa cells, the effect varied between six- and 12-fold ( $\mathrm{H}$. Mathys and W. Filipowicz, unpubl.).

Previous analyses of GW182 proteins identified domains responsible for interaction with Argonautes or localization to P-bodies (Behm-Ansmant et al. 2006; Till et al. 2007). However, no information was available about domains mediating the repression of protein synthesis. Deletion analysis combined with tethering assays identified $\Delta \mathrm{N} 1370$, the C-terminal fragment of TNRC6C encompassing DUF and RRM motifs, as a region with a dramatic, up to 20 -fold, repressive effect on the activity of an mRNA reporter. Noteworthy, repression of protein synthesis by $\Delta \mathrm{N} 1370$ was even stronger from that observed when a full-length TNRC6C was tethered to mRNA, raising a possibility that the N-terminal portion of TNRC6C may modulate inhibitory activity of the C-terminal part. The integrity of $\Delta \mathrm{N} 1370$ was essential to achieve maximal repression, since deletion of either the DUF domain or 80 C-terminal amino acids downstream from RRM decreased its inhibitory activity severalfold. Likewise, mutation of evolutionarily conserved aromatic residues of the RRM significantly lowered its inhibitory potential.

Previous work has shown that the GW182 protein in Drosophila S2 cells stimulates mRNA deadenylation and decay, but also has a direct inhibitory effect on mRNA translation (Behm-Ansmant et al. 2006; Eulalio et al. $2008 \mathrm{~b})$. We found that the inhibitory outcome of the tethering of each human TNRC6C paralog is also a combination of effects on mRNA translation and mRNA level. More detailed analysis of TNRC6C and its $\Delta \mathrm{N} 1370$ fragment showed that mRNA escaping the degradation remained polyadenylated. Thus the inhibitory effect on translation is not due to elimination of a stimulatory role of the poly(A)-binding protein $\mathrm{PABP}$ on translation initiation (Kahvejian et al. 2005) or mRNA “circularization" (Wells

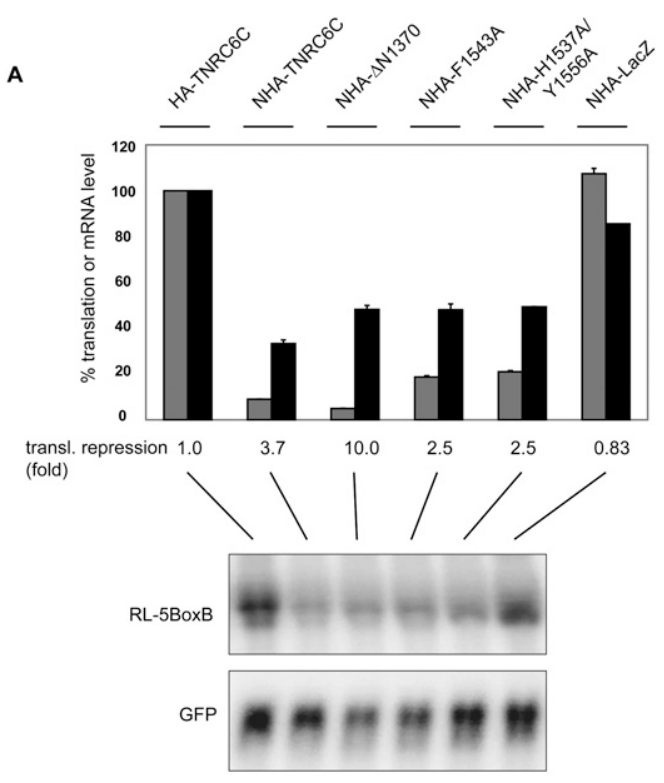

B

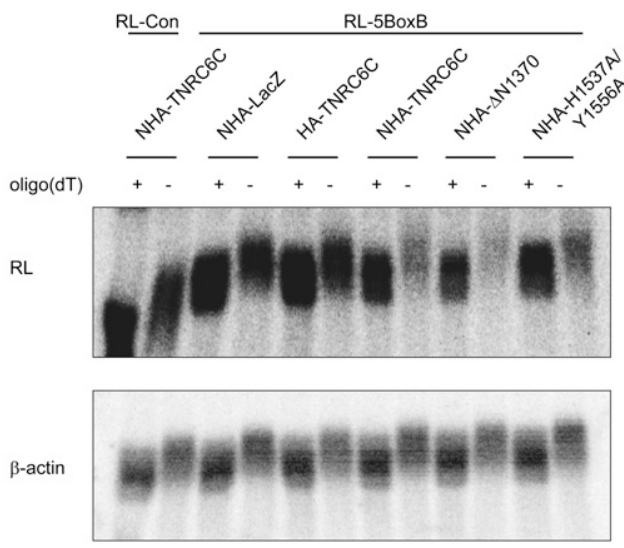

FIGURE 6. (Legend on next page) 
et al. 1998), but rather results from a more direct interference with the translation process. Interestingly, comparison of the repressive effects of $\Delta \mathrm{N} 1370$ and its mutants bearing amino acid substitutions in the RRM indicated that introduced mutations partially mitigate translational repression but have no appreciable effect on mRNA level. Hence, the RRM domain may play a more important role in translational repression rather than in mRNA destabilization. Our finding that $\Delta$ N1370 does not interact with the endogenous TNRC6 or AGO proteins also indicates that this fragment functions as an autonomous inhibitory domain and not by recruiting the endogenous miRNP complex to the reporter mRNA. This is consistent with the findings of Behm-Ansmant et al. (2006) that GW182 in Drosophila functions downstream from Agol and does not require Agol for inducing repression.

The $\Delta \mathrm{N} 1370$ fragment contains two domains, DUF and RRM, that are conserved in GW182-like proteins in many but not all metazoan organisms. The DUF domain is present in proteins of vertebrates, insects, and the worm B. malayi (Fig. 1) but not in Caenorhabditis elegans (Zhang et al. 2007). The function of the DUF domain is unknown, and limited mutagenesis of the domain carried out within the context of the $\Delta \mathrm{N} 1370$ fragment failed to identify amino acids important for the repression (Fig. 1B; data not shown). The RRM domain is conserved in all GW182 proteins of vertebrates and insects but is absent from the worm proteins. RRM domains are found in many RNAbinding proteins and are directly involved in the recognition of specific RNA substrates, primarily via aromatic amino acids of RNP1 and RNP2 motifs and via residues in

FIGURE 6. The $\Delta \mathrm{N} 1370$ fragment acts mainly as a translational repressor. (A) Tethering of $\Delta \mathrm{N} 1370$ causes strong repression of translation that is partially relieved by mutations in the RRM domain. Indicated proteins were coexpressed with reporter plasmids in HEK293 cells, and their effect on RL activity and RL-5BoxB mRNA stability was analyzed using extracts originating from the same transfections. (Upper panel) Effect of tethering on RL activity ([gray bars] normalized to FL) and RL-5BoxB mRNA level ([black bars] normalized to GFP mRNA). Values for transfection of HA-TNRC6C were set to $100 \%$. Calculated net repressive effects on translation are shown below the bars $(n=3$, with the exception of Northern analysis for NHA-H1537A/Y1566A and NHA-LacZ performed only twice and once, respectively). (Lower panels) Representative Northern analyses. (B) Treatment with RNase $\mathrm{H}$ in the presence of oligo(dT) results in faster mobility of both control mRNAs and mRNAs repressed by tethering. RL-Con and RL-5BoxB mRNAs were coexpressed in HEK293 cells with proteins indicated above the panels. RNA isolated from transfected cells was incubated with RNase $\mathrm{H}$ in the absence or presence of oligo $(\mathrm{dT})$ and analyzed by Northern blotting. The same blot was consecutively hybridized with probes specific for RL and $\beta$ actin mRNAs. Note that RL-Con mRNA is $220 \mathrm{nt}$ shorter than RL5BoxB. Hybridization signals (as measured by PhosphorImaging) in lanes representing incubations without oligo(dT) were found to be reproducibly weaker than those in the lanes with oligo $(\mathrm{dT})$. This is more pronounced for RL mRNAs than $\beta$-actin mRNA, and in the case of RL mRNAs, it applies to the same extent to mRNAs that do and do not undergo repression.
A

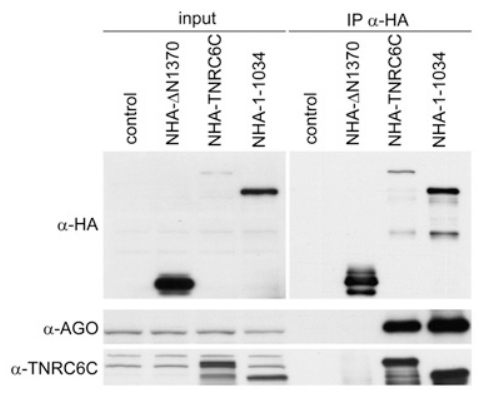

B
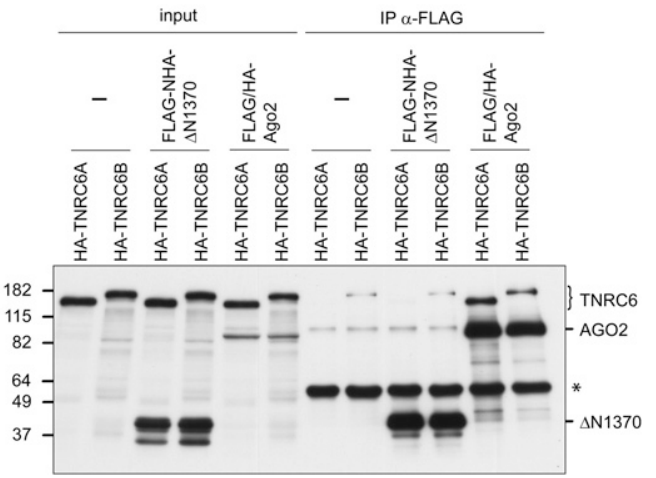

FIGURE 7. $\Delta$ N1370 does not interact with endogenous Ago and TNRC6C proteins. Cell extracts of HEK293 cells transiently expressing the indicated fusion proteins were incubated with anti-HA Affinity Matrix (Roche), and immunoprecipitated proteins (45\% of the total immunoprecipitate) were analyzed by Western blotting using the indicated Abs. Note that anti-AGO mAb $2 \mathrm{~A} 8$ recognizes all human AGO proteins (Nelson et al. 2007). Inputs represent 1\% (detection of Ago) and 5\% (detection of TNRC6C) of the cell extract used for IP. Nontransfected cells served as a control. (B) $\Delta$ N1370 does not interact with TNRC6A and TNRC6B proteins. Cell extracts of HEK293 cells transiently expressing indicated epitope-tagged proteins were incubated with anti-Flag M2-Agarose Affinity Gel (Sigma), and immunoprecipitated proteins $(45 \%$ of the total immunoprecipitate) were analyzed by Western blotting using anti-HA 3F10 mAb. Inputs represent $2 \%$ of the cell extract used for IP. Note that HA-TNRC6B unspecifically binds to $\alpha$-Flag beads and traces of it are present in IPs from both $\Delta \mathrm{N} 1370$-expressing and control cells. $\left({ }^{*}\right)$ The band most probably represents the IgG heavy chain.

loops interconnecting structural elements of the RRM (Clery et al. 2008). Several possible functions of the GW182 RRM in translational repression could be envisaged. The RRM may interact with the mRNA target and induce repression by contacting the cap or AUG regions of mRNA. Alternatively, the RRM could contact other RNA components participating in translation, such as initiator tRNA or ribosomal RNA. However, RRM domains were also shown to participate in protein-protein interactions (Clery et al. 2008). Hence, it is possible that a primary role of the GW182 RRM is to contact protein factors involved in mRNA translation. In future, it will be interesting to identify components of mRNA translation and/or decay machineries that interact with $\Delta \mathrm{N} 1370$. 


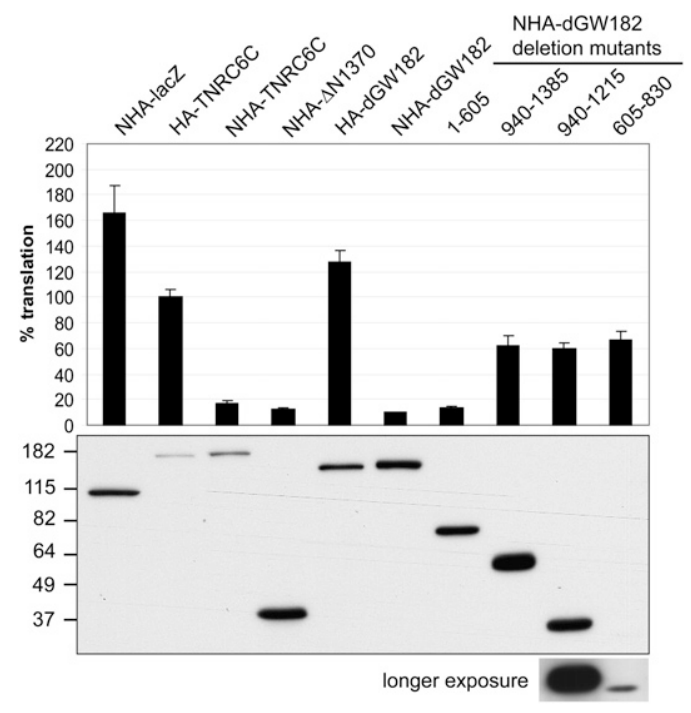

FIGURE 8. Effect of tethering of dGW182 and its deletion mutants on activity of RL-5BoxB reporter in human cells. (Upper panel) Tethering of dGW182 and its deletion mutants represses activity of RL-5boxB reporter in HEK293 cells. Indicated plasmids expressing human TNRC6C or Drosophila dGW182, or their mutants, were transfected to cells together with RL-5boxB and FL-Con. Normalized $\mathrm{RL}$ activity is indicated as the percentage of activity in cells expressing HA-TNRC6C set as 100\%. (Lower panel) Expression of fusion proteins analyzed by Western blotting using anti-HA Ab. (Inset at the bottom) Shows stronger exposure of the two lanes at far right, indicating that the Q-rich domain (mutant 605-830) is expressed at a much lower level than the remaining proteins. However, this low level of NHA-605-830 appears to be sufficient to achieve maximal repression since transfection of higher amounts of the plasmid encoding NHA-605-830 did not result in stronger repression (data not shown). The data represent means from three independent experiments. We note that transfection of control NHA-lacZ plasmid occasionally results in RL expression that is stronger (although not significantly) than that of another control reporter, HA-TNRC6C. The data were always normalized to RL expression in the presence of HA-TNRC6C, which we consider as a more appropriate control than NHA-lacZ.

In contrast to the $\mathrm{C}$-terminal $\Delta \mathrm{N} 1370$ fragment, which repressed activity of the target mRNA 10- to 20-fold, tethering of GW-rich and Q-rich domains had only an approximately twofold inhibitory effect on protein synthesis. This differs substantially from the situation in Drosophila cells, where three nonoverlapping regions of dGW182, GWrich and Q-rich domains, and the C-terminal fragment equivalent to $\Delta \mathrm{N} 1370$ were identified as regions repressing protein synthesis fivefold to sixfold upon tethering (Chekulaeva et al. 2009). The results of cross-species experiments indicated that tethering of a full-length dGW182 repressed protein synthesis in HEK293 cells as efficiently as TNRC6C (Fig. 8). Likewise, repression by full-length TNRC6C in Drosophila S2 cells was comparable to that of dGW182 (Chekulaeva et al. 2009). However, the contributions of individual domains to repression differed substantially between human and Drosophila proteins and cells. The GW-rich domain of dGW182 was the strongest repressor in human cells and was probably responsible for most of the activity of intact dGW182; the effects of the remaining domains were very limited. When different domains of human TNRC6C were tested in Drosophila S2 cells, the Qrich domain and the C-terminal $\Delta \mathrm{N} 1370$ fragment acted as strong repressors, with the GW-domain having the least effect (Chekulaeva et al. 2009). Hence, the N-terminal GWrich domain of dGW182 is a strong repressor in both S2 and HEK293 cells, while the analogous domain of TNRC6C has little effect in either cell type. In contrast, Q-rich domains from both dGW182 and TNRC6C were strongly inhibitory in Drosophila but not human cells, likely reflecting some specific aspects of the repression pathway in fly cells. Interestingly, the human $\Delta \mathrm{N} 1370$ fragment was strongly repressive in both systems, but its dGW182 counterpart had a major effect only in homologous Drosophila cells. The reasons for these protein-specific and cell-specific differences remain to be established, but the observations are consistent with a model proposed for Drosophila dGW182 according to which individual repressive domains of dGW182 contribute additively or cooperatively to the assembly of a larger repressive complex acting downstream from miRNPs (Chekulaeva et al. 2009). It will be interesting to dissect the repressive potential of the two other TNRC6 paralogs, TNRC6A and TNRC6B. The relative contributions to the repression of individual domains of these two proteins may be different from those established for TNRC6C.

\section{MATERIAL AND METHODS}

\section{Cell culture, transfection, and luciferase assays}

Human HEK293T cells (hereafter referred to as HEK293) were grown in Dulbecco's modified Eagle's medium (DMEM; GIBCO $\mathrm{BRL}$ ) supplemented with $2 \mathrm{mM}$ L-glutamine and $10 \%$ heatinactivated fetal calf serum (FCS). Generally, transfections were performed in triplicates in six-well plates with $\sim 60 \%$ confluent cells using Nanofectin (PAA Laboratories), following the manufacturer's instructions. Unless indicated otherwise, amounts of transfected plasmids per well were $50 \mathrm{ng}$ of indicated RL reporter, $300 \mathrm{ng}$ of FL-Con, and 20-100 ng of plasmid expressing indicated HA- or NHA-tagged proteins; when indicated, in transfections simultaneously used for Northern analysis, $200 \mathrm{ng}$ of peGFP-C1 (Clonetech) were also included. In some experiments, amounts of plasmids expressing TNRC6C deletion mutants were adjusted to obtain comparable levels of overexpressed proteins. Cells were lyzed $24 \mathrm{~h}$ post-transfection in Passive Lysis Buffer (PLB; Promega) to measure RL and FL activities by Dual-Luciferase Assay (Promega).

HeLa S3 cells were grown under similar conditions, but their transfection with siRNAs and reporter plasmids was performed in 24-well plates using Lipofectamine 2000 (Invitrogen) with proportionally lower amounts of indicated plasmids. Cells were trypsinized $24 \mathrm{~h}$ post-transfection and seeded into wells of a 6-well plate. After $48 \mathrm{~h}$, cells were lyzed as described above.

For RNAi, $100 \mathrm{nM}$ a single siRNA (GCCUAAUCUCCGUGCU CAATT and UUGAGCACGGAGAUUAGGCTG; sense and antisense 
strands, respectively) were used in the case of TNRC6A, and mixtures of two siRNAs, each $50 \mathrm{nM}$, were used for silencing of TNRC6B (GGCCUUGUAUUGCCAGCAATT, UUGCUGGCAAUACAAGGC CTT and GGAGUGCCAUGGAAAGGUATT, UACCUUUCCAUG GCACUCCTT) and TNRC6C (GCAUUAAGUGCUAAACAAATT, UUUGUUUAGCACUUAAUGCTT and CCAAGAGUUCUGUCU AAUATT, UAUUAGACAGAACUCUUGGTT). All siRNAs were obtained from Microsynth. Allstars Negative Control siRNA was purchased from QIAGEN.

\section{Plasmids}

RL-5BoxB, RL-3xBulgeB, RL-3xBulgeBmut, RL-Con, and FL-Con reporters (Pillai et al. 2005; Schmitter et al. 2006) and plasmid expressing NHA-LacZ (Pillai et al. 2004) were previously described. The plasmid encoding Flag/HA-Ago2 was a kind gift of Gunter Meister (Max Planck Institute for Biochemistry) (Meister et al. 2004).

Plasmids expressing HA- and NHA-tagged TNRC6A, TNRC6B, and TNRC6C were prepared as follows. For TNRC6A, the XhoINotI fragment excised from plasmid phrGFP/N1-GW182-A (kindly provided by E. Chan, Department of Oral Biology, University of Florida) (Eystathioy et al. 2002) was cloned into XhoI-NotIdigested pCI-NHA or pCI-HA vector (pCI-NHA or pCI-HA contain sequences encoding NHA or HA tags in pCIneo) (Pillai et al. 2004) to yield pCI-NHA-TNRC6A and pCI-HA-TNRC6A, respectively. The TNRC6A clones lack the N-terminal 312 amino acids (Eystathioy et al. 2002). For TNRC6B, the SalI-NotI fragment from the plasmid pDEST/Myc-GW182-B (kindly provided by G. Meister, Max Planck Institute for Biochemistry) (Meister et al. 2005) was cloned into SalI-NotI-digested pCI-NHA or pCI-HA vector to yield pCI-NHA-TNRC6B and pCI-HA-TNRC6B, respectively. Plasmids expressing HA- and NHA-tagged TNRC6C, pHATNRC6C, and pNHA-TNRC6C were prepared as follows: The EST clone KIAA1582 (from Kazusa DNA Research Institute, Japan) was digested with BstEII and NotI, and a 4.2-kb fragment corresponding to the downstream ORF part was eluted from agarose gel. The N-terminal ORF fragment was PCR-amplified using CGGAAT TCATGGCTACAGGGAGTGCCCAGGG and TGACTGAACCCAG AATTGCTATTTCC oligonucleotides as primers and digested with EcoRI and BstEII. The two fragments were inserted into a pCINHA vector pre-cut with EcoRI and NotI to yield pCI-NHATNRC6C. pCI-NHA-TNRC6C has an XhoI site between sequences encoding $\mathrm{N}$ and HA peptides, and two NheI sites: one upstream of the N-peptide-encoding sequence and another in the ORF. The plasmid was partially digested with NheI and the linearized DNA eluted from a gel. The DNA was then digested with XhoI. The desired 10.4-kb XhoI fragment was purified, the NheI and XhoI overhang sequences filled in with Klenow polymerase, and the plasmid religated.

Deletion mutants of TNRC6C were designed taking into account structure propensity calculations (http://bioinf.cs.ucl.ac.uk/disopred/). Mutants were obtained using the In-Fusion 2.0 Dry-Down PCR Cloning Kit (Clontech) and pCI-NHA-TNRC6C as a template. PCR products were cloned into linearized pCI-NHA. To prepare pFLAG-NHA- $\Delta$ N1370, sequence encoding NHA- $\Delta$ N1370 was PCR-amplified using pCl-NHA- $\Delta \mathrm{N} 1370$ as a template and AGGCT AGTCGACATGGACGCACAAACACGACG and AACCCTCACT AAAGGGAAGC oligonucleotides as primers. Following digestion with SalI and NotI, the fragment was inserted into SalI/NotI-digested expression plasmid pCIneo1FLAG (kindly provided by Michael Doyle of this laboratory).

Site-directed mutagenesis was performed by PCR using a pCINHA- $\Delta$ N1370 plasmid and partially overlapping primers containing desired mutations as described (Zheng et al. 2004). The original template was digested by the methylation-dependent enzyme DpnI and the PCR product was transformed into competent cells.

To generate pCI-NHA-dGW182, the sequence encoding NHAdGW182 in a modified version of plasmid pAC5.1- $\lambda$ N-HAGW182 (Behm-Ansmant et al. 2006) was PCR-amplified and cloned into pCIneo digested with NheI and NotI. Plasmids encoding deletion mutants were generated in a similar way as pCI-NHA-dGW182, using Drosophila plasmids expressing corresponding dGW182 mutants as templates (Chekulaeva et al. 2009). pCI-HA-dGW182 plasmid was generated from a pCI-NHAdGW182 plasmid by PCR amplification of the HA-dGW182 region, its digestion with SmaI and NotI, and cloning into pCIneo digested with NheI and NotI.

Correctness of all plasmids was verified by sequencing.

\section{Northern and RNase $\mathrm{H}$ analyses}

Total RNA was isolated from cells $24 \mathrm{~h}$ post-transfection using Trizol reagent (Invitrogen). Twelve micrograms of total RNA from each transfection were resolved in a formaldehyde- $1 \%$ agarose gel and blotted to the Nylon membrane for $48 \mathrm{~h}$ using $10 \times$ SSC. The RL- GFP- and $\beta$-actin-specific DNA probes $(0.9$, 0.75 , and $1.0 \mathrm{~kb}$ long, respectively) were ${ }^{32} \mathrm{P}$-labeled using the Random-primed DNA labeling Kit (Roche) and used for hybridization. Radioactivity was quantified with a PhosphorImager (Storm 860; Molecular Dynamics).

To analyze the polyadenylation status of mRNA, $20 \mu \mathrm{g}$ of total RNA isolated from transfected cells were annealed in the presence or absence of $2 \mu \mathrm{g}$ of oligo(dT) for $15 \mathrm{~min}$ at room temperature and then treated with RNase $\mathrm{H}$ (New England Biolabs) in the presence of RNasin Plus (Promega; $1 \mu \mathrm{L}$ per reaction) for $45 \mathrm{~min}$ at $37^{\circ} \mathrm{C}$, following the manufacturer's recommendations. RNA was purified with Trizol LS (Invitrogen), separated on a denaturing $1 \%$ agarose gel, and analyzed by Northern blotting.

\section{Antibodies, Western blotting, and immunoprecipitations}

Antibodies against human TNRC6C were raised in rabbits by Eurogentec, using a mixture of two peptides, TGSAQGNFTGHTKKT and TTIQDVNRYLLKSGG. The Abs were affinity-purified using individual peptides coupled to Sepharose. For Western analysis, aliquots of cell lysates in PLB were subjected to SDS-PAGE using a pre-cast 4\%-12\% gradient (Invitrogen) (Figs. 4 and 5) or 6\% linear polyacrylamide gels (Figs. 2, 3; 10\% for Fig. 8). Note that migration of investigated proteins in relation to protein size markers differs between these two types of gels. Anti-HA mAb 3F10 (Roche; 1:1000 dilution) or a combination of anti-TNRC6C rabbit Abs (1:1000) were used as primary antibodies, and goat anti-rat Ab coupled to HRP (MP Biochemicals; 1:8000) and anti-rabbit Ab (GE Healthcare, 1:10,000) as secondary Abs. Proteins were detected using ECL (GE Healthcare).

For HA epitope IP reactions, cells were lysed with $50 \mathrm{mM}$ Tris$\mathrm{HCl}\left(\mathrm{pH} \mathrm{7.5)}\right.$ containing $150 \mathrm{mM} \mathrm{KCl}, 5 \mathrm{mM} \mathrm{MgCl}_{2}, 1 \mathrm{mM}$ $\mathrm{CaCl}_{2}, 0.5 \%$ Triton X-100, $2 \mathrm{mM} \mathrm{DTT}, 40 \mathrm{U} / \mathrm{mL}$ RNaseOUT 
Recombinant Ribonuclease Inhibitor (Invitrogen), and EDTA-free Protease Inhibitor Cocktail (Roche). The cleared lysate was incubated with anti-HA Affinity Matrix (Roche). After washing with $10 \mathrm{mM}$ Tris- $\mathrm{HCl}$ (pH 7.5) containing $200 \mathrm{mM} \mathrm{KCl,} 5 \mathrm{mM}$ $\mathrm{MgCl}_{2}, 1 \mathrm{mM} \mathrm{CaCl}_{2}$, proteins associated with the beads were analyzed by Western blotting using anti-TNRC6C Abs, anti-HA mAb 42F13 (FMI Monoclonal Antibody Facility), and mAb 2A8 (Nelson et al. 2007) recognizing human AGO proteins (kindly provided by Z. Mourelatos, University of Pennsylvania School of Medicine). Flag IPs were performed using the Flag Tagged Protein Immunoprecipitation Kit (Sigma) according to the manufacturer's protocol. Immunoprecipitated proteins and input fractions were analyzed by Western blotting using anti-HA 3F10 antibody (Roche).

\section{Statistical analysis}

Data were tested for Normality using the Shapiro test. The null hypothesis for the Shapiro test is Normal data. Statistical significances were calculated on the Normally distributed data sets using a two-tailed paired Student's $t$-test. When the Shapiro test reported a $P$-value close to or below 0.05 (data are nonNormal), we performed the nonparametric Mann-WhitneyWilcoxon test. The error bars plotted throughout show the standard error of the mean (SEM). It follows from the central limit theorem that the distribution of sample means will be Normal even if the underlying sample distribution is not. So even for these cases, the error of the sample means will still be correct.

\section{ACKNOWLEDGMENTS}

We thank M. Chekulaeva, E. Oakeley, R. Parker, and N. Thoma for valuable discussions, and E. Chan, G. Meister, and Z. Mourelatos for reagents. We thank R. Pillai and C. Artus-Revel for initial contributions to this work. This work was supported by the EC FP6 Program "Sirocco." The Friedrich Miescher Institute is supported by the Novartis Research Foundation.

Received November 3, 2008; accepted January 22, 2009.

\section{REFERENCES}

Bagga, S., Bracht, J., Hunter, S., Massirer, K., Holtz, J., Eachus, R., and Pasquinelli, A.E. 2005. Regulation by let-7 and lin-4 miRNAs results in target mRNA degradation. Cell 122: 553-563.

Bartel, D.P. 2004. MicroRNAs: Genomics, biogenesis, mechanism, and function. Cell 116: 281-297.

Behm-Ansmant, I., Rehwinkel, J., Doerks, T., Stark, A., Bork, P., and Izaurralde, E. 2006. mRNA degradation by miRNAs and GW182 requires both CCR4:NOT deadenylase and DCP1:DCP2 decapping complexes. Genes \& Dev. 20: 1885-1898.

Bhattacharyya, S.N., Habermacher, R., Martine, U., Closs, E.I., and Filipowicz, W. 2006. Relief of microRNA-mediated translational repression in human cells subjected to stress. Cell 125: 1111-1124.

Bushati, N. and Cohen, S.M. 2007. MicroRNA functions. Annu. Rev. Cell Dev. Biol. 23: 175-205.

Chekulaeva, M., Filipowicz, W., and Parker, R. 2009. Multiple independent domains of dGW182 function in miRNA-mediated repression in Drosophila. RNA (this issue). doi: 10.1261/ rna.1364909.

Chendrimada, T.P., Finn, K.J., Ji, X., Baillat, D., Gregory, R.I., Liebhaber, S.A., Pasquinelli, A.E., and Shiekhattar, R. 2007.
MicroRNA silencing through RISC recruitment of eIF6. Nature 447: 823-828.

Clery, A., Blatter, M., and Allain, F.H. 2008. RNA recognition motifs: Boring? Not quite. Curr. Opin. Struct. Biol. 18: 290-298.

Ding, L. and Han, M. 2007. GW182 family proteins are crucial for microRNA-mediated gene silencing. Trends Cell Biol. 17: 411-416.

Ding, L., Spencer, A., Morita, K., and Han, M. 2005. The developmental timing regulator AIN-1 interacts with miRISCs and may target the argonaute protein ALG-1 to cytoplasmic P bodies in $C$. elegans. Mol. Cell 19: 437-447.

Eulalio, A., Behm-Ansmant, I., and Izaurralde, E. 2007a. P bodies: At the crossroads of post-transcriptional pathways. Nat. Rev. Mol. Cell Biol. 8: 9-22.

Eulalio, A., Rehwinkel, J., Stricker, M., Huntzinger, E., Yang, S.F., Doerks, T., Dorner, S., Bork, P., Boutros, M., and Izaurralde, E. 2007b. Target-specific requirements for enhancers of decapping in miRNA-mediated gene silencing. Genes \& Dev. 21: 25582570.

Eulalio, A., Huntzinger, E., and Izaurralde, E. 2008a. Getting to the root of miRNA-mediated gene silencing. Cell 132: 9-14.

Eulalio, A., Huntzinger, E., and Izaurralde, E. 2008b. GW182 interaction with Argonaute is essential for miRNA-mediated translational repression and mRNA decay. Nat. Struct. Mol. Biol. 15: 346-353.

Eystathioy, T., Chan, E.K., Tenenbaum, S.A., Keene, J.D., Griffith, K., and Fritzler, M.J. 2002. A phosphorylated cytoplasmic autoantigen, GW182, associates with a unique population of human mRNAs within novel cytoplasmic speckles. Mol. Biol. Cell 13: 1338-1351.

Filipowicz, W., Bhattacharyya, S.N., and Sonenberg, N. 2008. Mechanisms of post-transcriptional regulation by microRNAs: Are the answers in sight? Nat. Rev. Genet. 9: 102-114.

Giraldez, A.J., Mishima, Y., Rihel, J., Grocock, R.J., Van Dongen, S., Inoue, K., Enright, A.J., and Schier, A.F. 2006. Zebrafish MiR-430 promotes deadenylation and clearance of maternal mRNAs. Science 312: 75-79.

Huang, J., Liang, Z., Yang, B., Tian, H., Ma, J., and Zhang, H. 2007. Derepression of microRNA-mediated protein translation inhibition by apolipoprotein B mRNA-editing enzyme catalytic polypeptidelike 3G (APOBEC3G) and its family members. J. Biol. Chem. 282: 33632-33640.

Humphreys, D.T., Westman, B.J., Martin, D.I., and Preiss, T. 2005. MicroRNAs control translation initiation by inhibiting eukaryotic initiation factor 4E/cap and poly(A) tail function. Proc. Natl. Acad. Sci. 102: 16961-16966.

Jakymiw, A., Lian, S., Eystathioy, T., Li, S., Satoh, M., Hamel, J.C., Fritzler, M.J., and Chan, E.K. 2005. Disruption of GW bodies impairs mammalian RNA interference. Nat. Cell Biol. 7: 12671274.

Jakymiw, A., Pauley, K.M., Li, S., Ikeda, K., Lian, S., Eystathioy, T., Satoh, M., Fritzler, M.J., and Chan, E.K. 2007. The role of GW/Pbodies in RNA processing and silencing. J. Cell Sci. 120: 13171323.

Kahvejian, A., Svitkin, Y.V., Sukarieh, R., M’Boutchou, M.N., and Sonenberg, N. 2005. Mammalian poly(A)-binding protein is a eukaryotic translation initiation factor, which acts via multiple mechanisms. Genes \& Dev. 19: 104-113.

Kiriakidou, M., Tan, G.S., Lamprinaki, S., De Planell-Saguer, M., Nelson, P.T., and Mourelatos, Z. 2007. An mRNA $\mathrm{m}^{7} \mathrm{G}$ cap binding-like motif within human Ago2 represses translation. Cell 129: 1141-1151.

Kong, Y.W., Cannell, I.G., de Moor, C.H., Hill, K., Garside, P.G., Hamilton, T.L., Meijer, H.A., Dobbyn, H.C., Stoneley, M., Spriggs, K.A., et al. 2008. The mechanism of micro-RNA-mediated translation repression is determined by the promoter of the target gene. Proc. Natl. Acad. Sci. 105: 8866-8871.

Landthaler, M., Gaidatzis, D., Rothballer, A., Chen, P.Y., Soll, S.J., Dinic, L., Ojo, T., Hafner, M., Zavolan, M., and Tuschl, T. 2008. Molecular characterization of human Argonaute-containing 
ribonucleoprotein complexes and their bound target mRNAs. RNA 14: 2580-2596.

Li, S., Lian, S.L., Moser, J.J., Fritzler, M.L., Fritzler, M.J., Satoh, M., and Chan, E.K. 2008. Identification of GW182 and its novel isoform TNGW1 as translational repressors in Ago2-mediated silencing. J. Cell Sci. 121: 4134-4144.

Lim, L.P., Lau, N.C., Garrett-Engele, P., Grimson, A., Schelter, J.M., Castle, J., Bartel, D.P., Linsley, P.S., and Johnson, J.M. 2005. Microarray analysis shows that some microRNAs downregulate large numbers of target mRNAs. Nature 433: 769-773.

Liu, J., Carmell, M.A., Rivas, F.V., Marsden, C.G., Thomson, J.M., Song, J.J., Hammond, S.M., Joshua-Tor, L., and Hannon, G.J. 2004. Argonaute 2 is the catalytic engine of mammalian RNAi. Science 305: 1437-1441.

Liu, J., Rivas, F.V., Wohlschlegel, J., Yates III, J.R., Parker, R., and Hannon, G.J. 2005. A role for the P-body component GW182 in microRNA function. Nat. Cell Biol. 7: 1261-1266.

Lytle, J.R., Yario, T.A., and Steitz, J.A. 2007. Target mRNAs are repressed as efficiently by microRNA-binding sites in the $5^{\prime}$ UTR as in the 3' UTR. Proc. Natl. Acad. Sci. 104: 9667-9672.

Maroney, P.A., Yu, Y., Fisher, J., and Nilsen, T.W. 2006. Evidence that microRNAs are associated with translating messenger RNAs in human cells. Nat. Struct. Mol. Biol. 13: 1102-1107.

Mathonnet, G., Fabian, M.R., Svitkin, Y.V., Parsyan, A., Huck, L., Murata, T., Biffo, S., Merrick, W.C., Darzynkiewicz, E., Pillai, R.S., et al. 2007. MicroRNA inhibition of translation initiation in vitro by targeting the cap-binding complex eIF4F. Science 317: 1764-1767.

Meister, G., Landthaler, M., Patkaniowska, A., Dorsett, Y., Teng, G., and Tuschl, T. 2004. Human Argonaute2 mediates RNA cleavage targeted by miRNAs and siRNAs. Mol. Cell 15: 185-197.

Meister, G., Landthaler, M., Peters, L., Chen, P.Y., Urlaub, H., Luhrmann, R., and Tuschl, T. 2005. Identification of novel argonaute-associated proteins. Curr. Biol. 15: 2149-2155.

Nelson, P.T., De Planell-Saguer, M., Lamprinaki, S., Kiriakidou, M., Zhang, P., O'Doherty, U., and Mourelatos, Z. 2007. A novel monoclonal antibody against human Argonaute proteins reveals unexpected characteristics of miRNAs in human blood cells. RNA 13: $1787-1792$.

Nilsen, T.W. 2007. Mechanisms of microRNA-mediated gene regulation in animal cells. Trends Genet. 23: 243-249.

Nottrott, S., Simard, M.J., and Richter, J.D. 2006. Human let-7a miRNA blocks protein production on actively translating polyribosomes. Nat. Struct. Mol. Biol. 13: 1108-1114.

Olsen, P.H. and Ambros, V. 1999. The lin-4 regulatory RNA controls developmental timing in Caenorhabditis elegans by blocking LIN14 protein synthesis after the initiation of translation. Dev. Biol. 216: $671-680$.

Orom, U.A., Nielsen, F.C., and Lund, A.H. 2008. MicroRNA-10a binds the 5'UTR of ribosomal protein mRNAs and enhances their translation. Mol. Cell 30: 460-471.

Parker, R. and Sheth, U. 2007. P bodies and the control of mRNA translation and degradation. Mol. Cell 25: 635-646.

Peters, L. and Meister, G. 2007. Argonaute proteins: Mediators of RNA silencing. Mol. Cell 26: 611-623.

Petersen, C.P., Bordeleau, M.E., Pelletier, J., and Sharp, P.A. 2006. Short RNAs repress translation after initiation in mammalian cells. Mol. Cell 21: 533-542.

Pillai, R.S., Artus, C.G., and Filipowicz, W. 2004. Tethering of human Ago proteins to mRNA mimics the miRNA-mediated repression of protein synthesis. RNA 10: 1518-1525.
Pillai, R.S., Bhattacharyya, S.N., Artus, C.G., Zoller, T., Cougot, N., Basyuk, E., Bertrand, E., and Filipowicz, W. 2005. Inhibition of translational initiation by Let-7 MicroRNA in human cells. Science 309: 1573-1576.

Rehwinkel, J., Behm-Ansmant, I., Gatfield, D., and Izaurralde, E. 2005. A crucial role for GW182 and the DCP1:DCP2 decapping complex in miRNA-mediated gene silencing. RNA 11: 1640-1647.

Rehwinkel, J., Natalin, P., Stark, A., Brennecke, J., Cohen, S.M., and Izaurralde, E. 2006. Genome-wide analysis of mRNAs regulated by Drosha and Argonaute proteins in Drosophila melanogaster. Mol. Cell. Biol. 26: 2965-2975.

Schmitter, D., Filkowski, J., Sewer, A., Pillai, R.S., Oakeley, E.J., Zavolan, M., Svoboda, P., and Filipowicz, W. 2006. Effects of Dicer and Argonaute down-regulation on mRNA levels in human HEK293 cells. Nucleic Acids Res. 34: 4801-4815.

Schneider, M.D., Najand, N., Chaker, S., Pare, J.M., Haskins, J., Hughes, S.C., Hobman, T.C., Locke, J., and Simmonds, A.J. 2006. Gawky is a component of cytoplasmic mRNA processing bodies required for early Drosophila development. J. Cell Biol. 174: 349358.

Sen, G.L. and Blau, H.M. 2005. Argonaute 2/RISC resides in sites of mammalian mRNA decay known as cytoplasmic bodies. Nat. Cell Biol. 7: 633-636.

Standart, N. and Jackson, R.J. 2007. MicroRNAs repress translation of m7Gppp-capped target mRNAs in vitro by inhibiting initiation and promoting deadenylation. Genes \& Dev. 21: 1975-1982.

Till, S., Lejeune, E., Thermann, R., Bortfeld, M., Hothorn, M., Enderle, D., Heinrich, C., Hentze, M.W., and Ladurner, A.G. 2007. A conserved motif in Argonaute-interacting proteins mediates functional interactions through the Argonaute PIWI domain. Nat. Struct. Mol. Biol. 14: 897-903.

Tolia, N.H. and Joshua-Tor, L. 2007. Slicer and the argonautes. Nat. Chem. Biol. 3: 36-43.

Vasudevan, S., Tong, Y., and Steitz, J.A. 2007. Switching from repression to activation: MicroRNAs can up-regulate translation. Science 318: 1931-1934.

Vasudevan, S., Tong, Y., and Steitz, J.A. 2008. Cell-cycle control of microRNA-mediated translation regulation. Cell Cycle 7: 1545-1549.

Wakiyama, M., Takimoto, K., Ohara, O., and Yokoyama, S. 2007. Let-7 microRNA-mediated mRNA deadenylation and translational repression in a mammalian cell-free system. Genes \& Dev. 21: 1857-1862.

Wells, S.E., Hillner, P.E., Vale, R.D., and Sachs, A.B. 1998. Circularization of mRNA by eukaryotic translation initiation factors. Mol. Cell 2: 135-140.

$\mathrm{Wu}$, L. and Belasco, J.G. 2005. Micro-RNA regulation of the mammalian lin-28 gene during neuronal differentiation of embryonal carcinoma cells. Mol. Cell. Biol. 25: 9198-9208.

$\mathrm{Wu}$, L. and Belasco, J.G. 2008. Let me count the ways: Mechanisms of gene regulation by miRNAs and siRNAs. Mol. Cell 29: 1-7.

Wu, L., Fan, J., and Belasco, J.G. 2008. Importance of translation and nonnucleolytic ago proteins for on-target RNA interference. Curr. Biol. 18: 1327-1332.

Zhang, L., Ding, L., Cheung, T.H., Dong, M.Q., Chen, J., Sewell, A.K., Liu, X., Yates III, J.R., and Han, M. 2007. Systematic identification of C. elegans miRISC proteins, miRNAs, and mRNA targets by their interactions with GW182 proteins AIN-1 and AIN-2. Mol. Cell 28: 598-613.

Zheng, L., Baumann, U., and Reymond, J.L. 2004. An efficient onestep site-directed and site-saturation mutagenesis protocol. Nucleic Acids Res. 32: e115. 

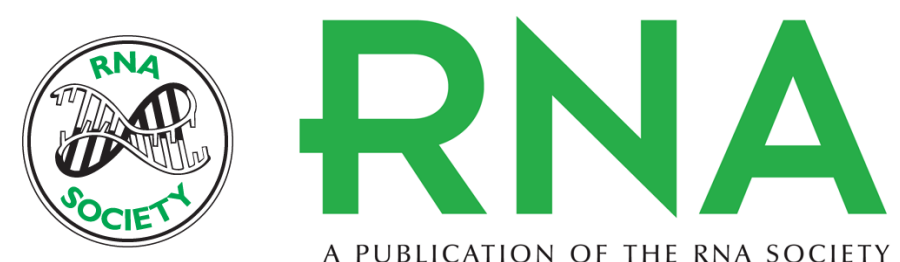

A PUBLICATION OF THE RNA SOCIETY

\section{Importance of the C-terminal domain of the human GW182 protein TNRC6C for translational repression}

Jakob T. Zipprich, Sankar Bhattacharyya, Hansruedi Mathys, et al.

RNA 2009 15: 781-793 originally published online March 20, 2009

Access the most recent version at doi:10.1261/rna.1448009
Related Content Mammalian GW182 contains multiple Argonaute-binding sites and functions in microRNA-mediated translational repression
Koji Takimoto, Motoaki Wakiyama and Shigeyuki Yokoyama
RNA June, 2009 15: 1078-1089 A C-terminal silencing domain in GW182 is
essential for miRNA function
Ana Eulalio, Sigrun Helms, Christoph Fritzsch, et al.
RNA June, 2009 15: 1067-1077 Multiple independent domains of dGW182 function
in miRNA-mediated repression in Drosophila
Marina Chekulaeva, Witold Filipowicz and Roy Parker
RNA May , 2009 15: 794-803

References This article cites 61 articles, 25 of which can be accessed free at:

http://rnajournal.cshlp.org/content/15/5/781.full.html\#ref-list-1

Articles cited in:

http://rnajournal.cshlp.org/content/15/5/781.full.html\#related-urls

License

Email Alerting

Receive free email alerts when new articles cite this article - sign up in the box at the Service 